\title{
A comprehensive study on energy meters and power tampering attempts
}

\author{
Manoj Saini, Shagufta Khan \\ School of Electrical, Electronics and Communication Engineering, Galgotias University, Greater Noida, India
}

\begin{tabular}{l}
\hline \hline Article Info \\
\hline Article history: \\
Received Jun 30, 2021 \\
Revised Aug 9, 2021 \\
Accepted Aug 20, 2021 \\
\hline
\end{tabular}

Keywords:

AT\&C losses

Electricity

Energy meters

MDMS

Power tampering

Smart meters

\section{Corresponding Author:}

Manoj Saini

School of Electrical, Electronics and Communication Engineering

Galgotias University

Plot No. 2, Yamuna Expy, Opposite Buddha International Circuit

Sector 17A, Greater Noida, Uttar Pardesh, India

Email: engg.manojsaini@gmail.com

\begin{abstract}
Electricity is the basic need of today's scenario. In the $21^{\text {st }}$ generation, growth and development is totally dependent on electricity. Thus, measurement of consumption of electricity becomes much more important. Energy meter used to measure consumed electricity by building or electrical equipment of various end users. This paper focuses on review of energy meters and power tampering attempts. It will highlight the development of meters from electromechanical meters to smart meters. The need of an era is to develop a more reliable and intelligent smart energy meters. This paper also discussed type of power tampering efforts in energy meters for power theft. The concept of smart meters for removing the power tampering efforts is also discussed.
\end{abstract}

This is an open access article under the CC BY-SA license.

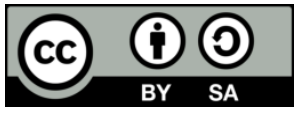

\section{INTRODUCTION}

Electricity has become the soul need of day to day life thus its proper utilization becomes much more necessary. The need of power in India is estimated to increase about 300GW from 120GW by 2021-22. Energy is the second largest cost of operating a building in India. We need a more reliable, intelligent, user friendly and efficient metering system to fulfill the required needed power. But poor distribution of electricity is because of the aggregate technical and commercial losses (AT\&C losses) [1], [2].

In 2014-15 AT\&C losses were about 24.65\%. In some Indian states AT\&C losses are high due to low collecting efficiency. The power theft by means of tampering with the meter is due to absence of energy audit and accounting records of an end user. These losses increase during peak hours. Collection of reading is difficult part of billing. This procedure has drawbacks due to involvement of human resources, time consuming and tiring, because of it involves involvement of an employ who visits the costumer for the collection of readings on a particular basis. This may also lead to corruption. For a proper management of electricity consumption, we want correct metering, detection of illegal collection activities and implementation of accurate tariff and billing system. Load shedding and low voltage during peak hours is increased due to high energy demand.

All these losses can be reducing to an extent using the advanced technology of energy metering, that is, smart and prepaid energy meters. Smart metering technology comprises of features like detection of energy theft, remote fault detection, to control power quality. It should also give detailed information of power consumption. This paper will cover the major aspect of development from electromechanical to smart 
meters. New features, new indicators, new application has been inserted in these smart meters that are not in a conventional energy meter [3]. The whole world is still struggling with the opportunities and challenges of meter reading/billing system [4]. A new significance has been stated for estimating electricity consumption using meter image using HoG and SVM [5].

A very good metric of collecting information of the meter by image processing method was also revealed [6]. In today's era, technology has advanced a lot in the field of electrical distribution and utilization; still we are facing lot of challenges. To overcome these challenges, we need precise weapons like move from analog system to digital system because digital system has many advantages [7]. A new energy meter which automatically sends its energy consumption records to the utility. GSM and IoT are two boons of science that have gained a lot of help in wireless data transmission b/w energy meter user or utility [8].

Power companies have been struggling with direct consumers with their consumers for a long time. But right now, he has got success in the last decade. The Indian power sector is facing lot of problems due to power theft and network losses. Prime is our traditional billing system, which is inaccurate, lack of flexibility, not reliable. Due to these reasons, efforts are on to make the billing system automatic day and night [9]. There has been some improvement in meter reading, but along with this, the process of bill payment is also going on our traditional way. There is a lot of improvement in that too. This requires an agent come to customer place to pay attention to meter reading and make a report based on it. After the report tells you how much you have to pay, it is a long process and the longer the process is, the more chances of making mistakes. In the absence of communication systems, what are the problems we are facing and how do we get the benefit out of their problem or this is presented in this paper [10].

Solution of the problems caused by traditional energy meter in Bangladesh has been solved by using prepaid energy meter is explained in this paper [11]. Demand side management (DSM) can be achieved, with indirect involvement [12]. The demand based smart metering system comprises two separate modules, a smart meter at the consumer end and a server computer at the utility provider side. A new concept to prevent theft and wireless control of smart digital energy meter using GSM with GUI is found effective in practice [13].

\section{EARLY ENERGY METERS}

Another method William Edward Ayrton and John Perry in 1881, based on the oscillation/motion of pendulum proportional to applied load was introduced, called Pendulum energy meter. A more advanced pendulum meter was introduced by Herman Aron in 1884, without knowing about earlier invention. There were two pendulums wounded by current coil in opposite direction which in turn was connected to voltage. One pendulum drove the other faster. Pendulums were interchanged every minute so that initial difference can be compensated. These types were expensive and used for measurement of DC current only.

This pendulum meters were replaced by Thomson Wattmeter, using motor in place of pendulum. Iron less motor meter developed by Elihu Thomson in 1889. Rotor of the motor is excited by voltage coil and a resistor using a commutater. Driving torque was proportional to load and braking torque was provided by permanent magnet. Commutater causing high losses and it was only used for DC. The basic disadvantage of DC system was that the voltage level cannot be changed, thus not used for large system.

In 1889, Otto Tituzz Blathy developed metallic rotating body like cylinder/disk acted by 2 magnetic fields displaced in phase from one another electrical meter for alternating currents. In 1894, Shallen Berger developed an induction type meters. It had a current and voltage coil situated on opposite disc's side. It had no adjustment for power factor. By the end of 19th century, the weight and dimension of energy meter was reduced, increasing the load range, power factor adjustment, reduction of friction using a pivot bearing and increasing the stability by using improved brake magnet. Till now, the use of three phase induction meters started consisting of a measurement system using one to three disks.

By the starting of 20th century, the need of electricity increased and new meters such as multi tariff meter using switches, the prepayment meter was invented by maxigraph. In 1934, the Trivector meter was developed by Landis and Gyr which measured active and reactive energy. Standards and metering accuracy in 1910, first metering standard ANSI C12 was developed. Its Preface says: "While the Code is naturally based upon scientific and technical principles, the commercial side of the metering has been constantly kept in mind as of very great importance".

\section{ERA OF ENERGY METERS}

The first attempt for the calculation of energy consumption was done by Samuel Gardiner [USA] using lamp hour meters in 1872. It had a clock with start stop mechanism. It calculates energy supplied to lamp hour along with time. In 1881, Thomas Alva Edison invented an electricity meter which used an 
electrolytic cell. At beginning of measurement period, a copper strip was used which was weighted accurately. When the current passed through electrolyte, deposition of $\mathrm{Cu}$ occurred. End of the day, the bill was calculated by find out the difference $\mathrm{b} / \mathrm{w}$ the weight of $\mathrm{Cu}$ plate. This meter was not widely accepted because of not being user friendly for the measurement and was difficult for customer to read. They could measure in terms of ampere-hour and were not suitable for fluctuating voltage. Later on Edison introduced counting mechanism in it. The era of energy meters is shown in Table 1.

\section{ASSORTMENT OF ELECTICITY METERS}

Energy meters continuously works by calculating speedy V and I to calculate energy consumption. For more than 200 amperes of load that is higher load current transformers are used. Meters can be broadly classified into various categories.

\subsection{Electromechanical meters}

Thomson electric meter most regular electric meter invented by Elihu Thomson in 1888, which falls under this category. Number of revolutions of rotating disc is counted in this meter. It consists of three types of magnets having two electromagnets, one series electromagnet and other shunt electromagnet. On the series magnet (U-shaped) current coil is mounted whereas on shunt electromagnet (M-shaped) pressure coil is mounted. Pressure coil is connected across the supply. Copper shunt bands are provided on shunt magnet so that phase displacement of 90 whereas flux set up by shunt and series magnet. CC is connected in series with load.

In the moving system, spindle with pivoted bearing screw at bottom, carry rotating disc. Recording mechanism connected to the top of the spindle. The driving force produced due to the reaction $\mathrm{b} / \mathrm{w}$ the flux produced by eddy current due to shunt and series magnet. A light load adjustment is provided on spindle to overcome friction losses. A, C shaped permanent magnet provide braking system. The braking magnet is so placed that the disc placed revolves in the air gap of two poles of magnet. This magnetic field induces an eddy current in disc, which reacts with main magnetic field and creates braking effect. By charging position of braking magnet, speed of rotation of disc is adjusted. Figure 1 shows the components of the moving disk type energy meter.

Table 1. The era of energy meters

\begin{tabular}{|c|c|c|c|c|}
\hline S. No & Year & Name & Discovered & Features \\
\hline 1 & 1881 & Electrolytic Meter & Thomas Alva Edison & $\begin{array}{l}\text { Electrochemical effect of current System, Meter reading was } \\
\text { difficult for the utility and impossible for the customer. }\end{array}$ \\
\hline 2 & 1884 & Pendulum Meter & Hermann Aron & $\begin{array}{l}\text { Very Expensive because they contained two clocks. Measure } \\
\text { ampere-hours, but could be used only for direct current. }\end{array}$ \\
\hline 3 & 1889 & Recording Wattmeter & Elihu Thomson & Used mainly for DC \\
\hline 4 & 1894 & Induction Meter & $\begin{array}{l}\text { Oliver Blackburn } \\
\text { Shallenberger }\end{array}$ & $\begin{array}{l}\text { Current and Voltage coils located on opposite sides of the disc } \\
\text { and two permanent magnets damping the same disc, It was } \\
\text { also large and heavy, weight } 41 \text { pounds. It had a drum-type } \\
\text { register. }\end{array}$ \\
\hline 5 & 1899 & AC Watthour & Ludwig Gutmann & No Power Factor adjustment. \\
\hline 6 & 1914 & Meter Blathy & Otto Titusz Blathy & Low price and excellent reliability. \\
\hline 7 & 1934 & Meter Trivector & Landis and Gyr & Measure active and reactive power. \\
\hline
\end{tabular}

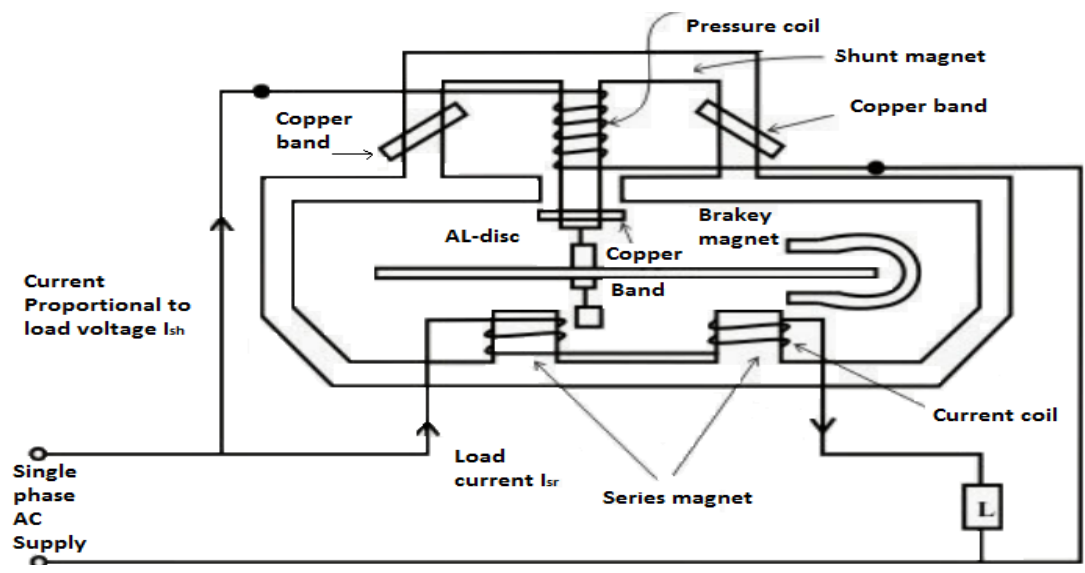

Figure 1. Moving disk energy meter 
This registering system consist train of gears, driven pinions or worm gears. This indicates on dials the number of times the disc has turned. Add together or integrate all instantaneous power values in this way total energy over a time period is calculated. The right-hand dial pointer in the register on $1 \mathrm{KWh}$. The second dial from right is $10 \mathrm{KWh}$, third is $100 \mathrm{KWh}$ and fourth is $1000 \mathrm{KWh}$. Sometimes $1 / 100$ and $1 / 10$ $\mathrm{KWh}$ are also provided. This arrangement is known as cyclometer register.

It consists of a moving disc that undergoes wear and tear with time. The moving disc also consumes some electricity which is not recorded. The dust, humidity and dirt affect the accuracy of electromechanical meter. Sudden shock may cause also cause mis-calibration of meter. Figure 2 shows meters registration over the years of the services.

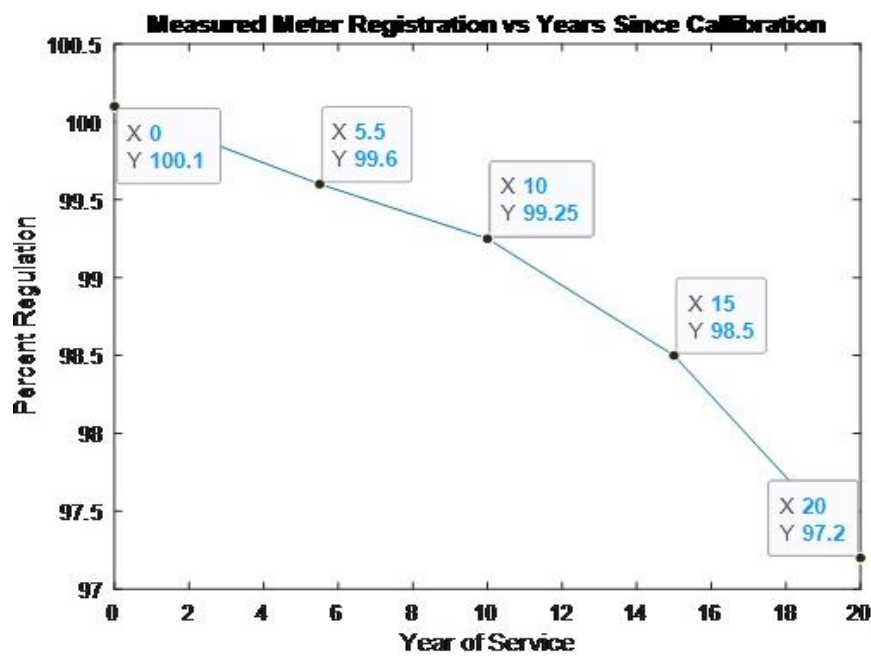

Figure 2. Meter registration over the years of Service

The effort made to stop the power tampering in this type of meter is done by the poly carbonate security seals and temper resistant hardware on the body of the meter. But even all these efforts are not able to stop the theft. Because there is duplication of security seals and tempers resistant hardware. Not only this, tools of this kind are being prepared in the market. Tools whose help in security sales and hardware can be easily opened without tempering the original protection device and tampering are done with the energy meter in any way.

Few common power theft activities are point out here; with the help of these a customer steals power without tampering the meter. Power theft in voltage circuit, by-passing of energy meter outside style, inside style of by-passing meter, power theft by drilling holes on meter, theft by insertion of film into meter, direct tapping from incoming wires. Along with this, power theft is also being done by bribing employees of power companies. Employees provide the original security seals to the customer or tell them how to open security seals or some time they provide tools to open the security seals and temper resistant hardware. In this manner an end user commits a theft incident, which makes it very difficult to catch by electromechanical and electronics meters, there is only one method to prevent this kind of power pilferage by use of smart energy meter.

\subsection{Electronic meters}

When the energy is displayed on LED or LCD display is called electronic meter. Electronic meters record in addition to measuring energy, other parameters like instantaneous and maximum rate of usage demands, voltage, cos $\phi$ and $Q$ used. Electronic meters are better than other type of meter as they do not cosists of moving parts. They also provide additional information. Thus, electronic meters consume less electricity and give more accurate reading. They can be classified into analog and digital electronic meter. NYSERDA and DHCR New York State agencies first evaluated electronic meters. The electronics meter is a bit good as comparison of electromechanical meters because it blocks attempts to steal what was in the disc with the electrochemical meter. But still the power is being stolen in the power electronics energy meter by different way like partial earth fault tampering, theft by missing neutral method, cross potential method of performing power theft. 


\subsection{Analog energy meters}

Using V divider and current transformer analog meter calculate the V, I of each phase. These analog values are converted into digits using analog to digital converter, which in turn are converted to frequency signal using frequency converter. Energy consumption is calculated by integrated these frequency signals over a time period. Figure 3 shows the circuit diagram along with connection with line or all the components interconnection of analog energy meters.

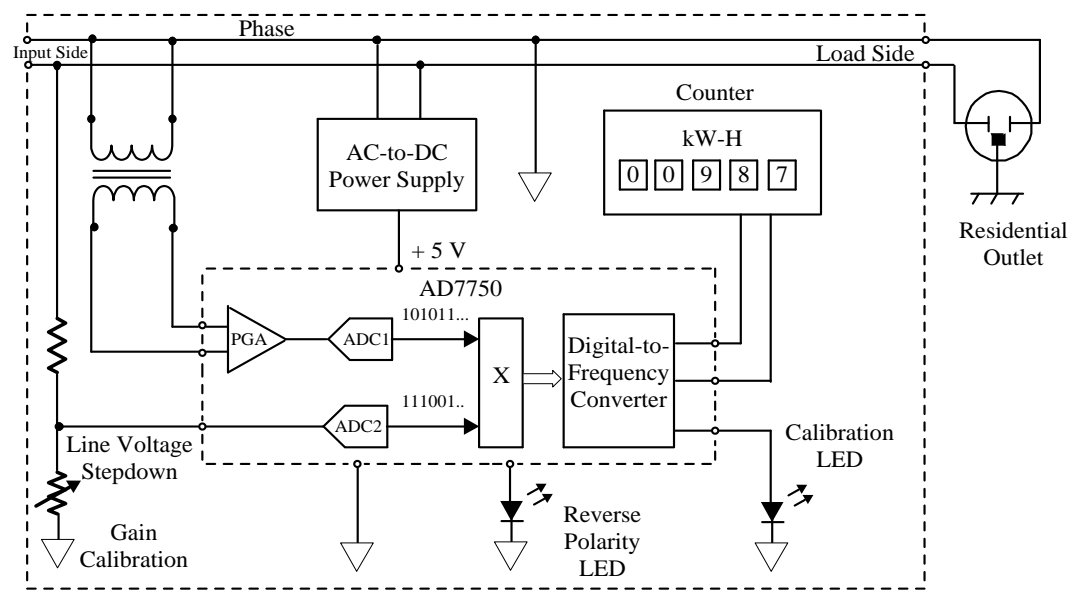

Figure 3. Circuit diagram of analog energy meter

Power is stolen by many ways in the analog energy meter by tampering the meter counter, frequency circuit, and printed circuit board. Sometime the valuable components reference value can be replaced by another value, fake LED indication is done by bypassing the main LED. The theft is done so cleanly that there is no evidence that tempering has occurred with the meter.

\subsection{Digital energy meters}

Block diagram of digital energy meters is shown in Figure 4. High speed microprocessors are used in digital energy meters. High resolution analog to digital converters are used with current and voltage transducer. The phase angle b/w I and V is calculated by microprocessor. The data is stored in non-volatile memory EEPROM. The reliability and accuracy can be verified using ANSI-C12 standards. These are more accurate and thus reduce reading and interpolation error . As there is no moving part hence they are free from wear and shock error. They are portable in size. They have high input impedance. Meter loading effect is also reduced. The LCD display works on battery, it becomes difficult to read as the readings are dim when the battery is low. There can be fluctuating errors. If the voltage is increased beyond the limit, the meter will be damaged. The heating of meter can alter the properties thus resulting in error in measured value. A quantization error can be caused due to word length, thus noise is produced.

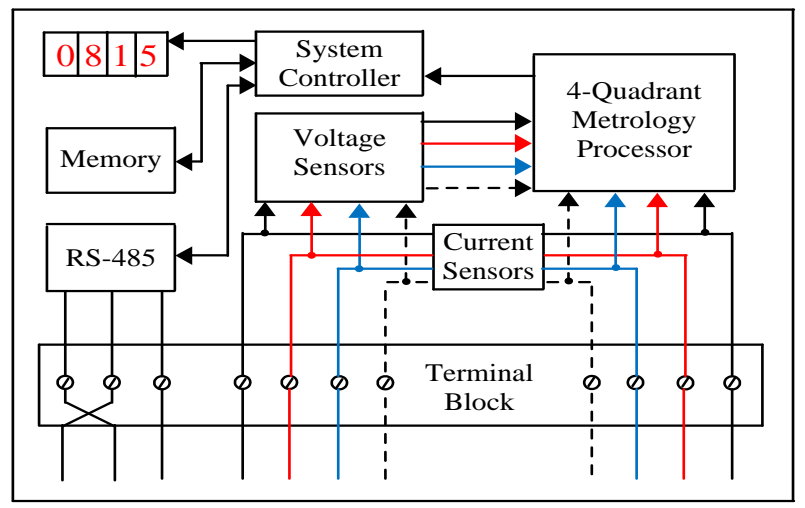

Figure 4. Digital energy meter 


\subsection{Smart electricity meter}

They are new generation energy meters. They send readings of energy consumption to energy supplier. It is a two way communicating device. They uses a much secure communication network to send readings automatically and wirelessly thus the process of manual handling of meter comes to an end. Software's upgrading and other important messages can also be send from the suppliers side. Modems are installed in these energy meters which help to improve communication system. The consumption of electricity is recorded in hour interval or less, and is communicated daily for billing purpose. Communication from meter to network can be both via wire or wireless.

In 1972, Theodore George Paraskevakos developed a digital transmission sensor monitoring system using security and fire alarm system. Metretek developed $1^{\text {st }}$ fully automated remote meter reading system in 1977. It gives more accurate billing system. It makes us to better understand our usage. One can monitor their bills by having the complete information about the usage. When we were the energy is wasted, we can save energy by using smart energy meters. In case of issues such as low voltage period can be reported to ensure better supply. More competitive time of use tariffs can be created by suppliers with cheaper rates at off peak times. With the introduction of smart meters, meters are now exposed to cyber threats. Some cases are registered of reprograming of device to show wrong readings. Wireless meter emits pulsed radiofrequencies which causes health problem. Smart meters had also been reported of causing fires. They could be more costly than the savings they are giving to the customer. They are also causing unemployment by causing people out of work. Privacy threat of personal data is also a problem. By directional communication features is available, this feature help in various kind of load forecasting analysis and record tampering attempt by power stealers with compete avoidance. Switching easy and faster just within an hour based on the past consumption data of the consumer.

In electronic energy meters, tempering is done by different-2 manner. The meter display, signal processing unit can be tampered. The frequency of a crystal oscillator can be changed by changing the oscillator, in addition to this tempering indicator LED can also be replaced. Thus, by looking at the meter, we cannot tell with our naked eyes whether there has been any tampering with the meter or not. In this way, without taking the energy meter to the lab, to find that there is some kind of tempering with it is not possible or very difficult. Taking action in this manner is a time taking process and by then a customer has committed a lot of theft. Magnifying glass is used to catch the theft, but sometimes the user so cleverly erases all the evidence, that even with the help of magnifying glass we cannot find out whether there is a tempering with the meter or not.

\subsection{Prepaid energy meter}

Most of the electromechanical energy meters are installed in the consumer's premises in India. In India customer is stealing power by tampering with these electromechanically energy meters, the features are gradually being updated. Now a day's these types of meters are being replaced with the prepaid energy meters along with digital features so that a consumer does not carry out such incidents in future. Non-timely release of electricity bills, incorrect meter readings, power theft by end users or end user consumers are not interested in paying their electricity bills, electricity department is losing a lot of income. Smart, Prepaid energy meters can eliminate the above said losses. In this way profit of the utility company can be increased. This type of energy meters helps electricity utility to collect all consumer bills timely. Above said meter mean we are using a meter as like smart/prepaid mobile phone.

Energy meter has a prepaid card just like a SIM card of a mobile phone. This card communication together with its technical system provides help in its program with utility. When card balance completes, then consumer's connection is automatically cut off from the power supply. Power companies can recharge their consumer's prepaid energy meter card through mobile communication based on their customer's request. Prior billing reduces the problem of unpaid bills and also correct mistakes that were made in the meter reading from the meter reader and this ensures an assured fix justified revenue for the utility.

Automatic meter reading systems and power quality monitoring system's manufacturers are taking advantage of electronic booster semiconductor chips technologies. These technologies are integrated to design new meters and devices. So that it can stop the power theft. Network technologies are being driven by the demand for interconnection of computer users all over the world. AMR and power monitoring system using these advanced technologies of the greatly spreading the monitoring system. Prepaid energy meters are not limited to meter readings of their consumers. It provides lot of information like recharge related information, when did consumer recharge? How much has he used and how much more has happened? It holds all kind for consumption details with information exchange with utility.

Prepaid energy meter will help a lot in making micro-grid and smart grid very smarter because this idea will be very important for new research. Many researchers have done a very good work in this area. The use of this technology has proved more useful for consumers in the UK who have had poor payment records, 
have not been able to deposit money on time in 1996. The design describes by Kwan, how data is transferred $\mathrm{b} / \mathrm{w}$ personal computers and smart computers that are owned by Utility using half duplex mode. A 3-tier smart card secure solution is explained by Raad in 2007, that uses IP-based controller along with energy meter for providing online controlling and monitoring of electricity consumed.

\subsection{Prepaid energy meter desiging}

The proposal idea not only changes the meters, but also tells us that we should constantly upgrade our prepaid energy meters. All the designs that come in this way will have an energy meter, a prepaid card and an LCD display and a communication medium to make prepaid energy meters.

\subsubsection{Energy meter}

Based on the connected load, the disk/rotor of rotate and electromechanical energy meter calculates total consumed energy. Electronics meter have all these internal components connected with a microcontroller. Programmed microcontroller calculate how much energy the particular user consumed; balance of the prepaid card is adjusted accordingly.

\subsubsection{Communication module and prepaid}

Utility and consumer both constantly get information about prepaid card balance and power consumption using communication module. Prepaid card design is very is important addition part inside the meter. Programming is done in advance in microcontroller by fixing the tariff structure. As soon as a load is connected, the meter prepaid card keeps converting these items into a continuous expenditure and reducing the mean amount. Prepaid card amount gradually becomes zero with energy consumption and customers can recharge their card of meter with the help of internet. The utility company recharges the prepaid card of the customer energy meter on receipt of the recharge amount. Card generates a signal to the conductor and the customer's supply becomes healthy.

\subsubsection{Contactor}

A local contactor acts as a link b/w the utility supply and consumer load. The contractor opening and closing of depends on how much balance is there on card. As long as the balance is more than zero in the card, it will remain in a closed state and the customer will continue to get uninterrupted power supply. When the balance becomes zero in the card, it will open and the supply will also be disconnected. Hence, electricity coming to the energy meter but they do not reach the load. This is because the balance of the prepaid card has been become zero. The contactor remains open and the load cannot connect to the supply. In this way, the contactor continues to consume some power, which is not included in bill/consumption of the end user.

\subsubsection{Working}

Figure 5 block diagram explain the working. The utility fed supply to energy meter, a prepaid card embedded on meter. Card gives high/low signal i.e. close/open signal to contactor based on balance in it. Prepaid energy meters were able to control power theft for a very long time. But due to the problem of data management data handling data analysis, we are still struggling.

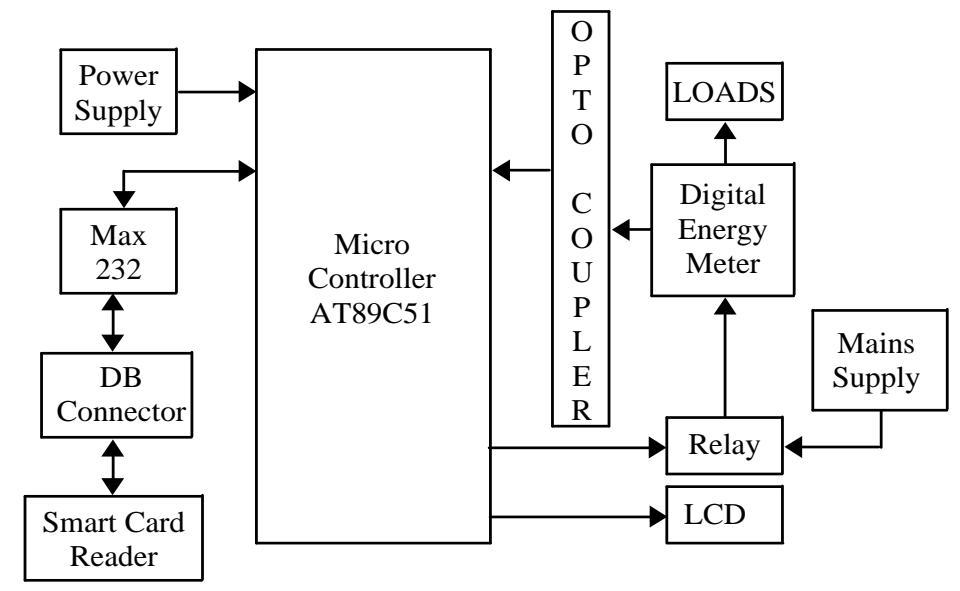

Figure 5. Digital energy meter 


\subsection{Demand based smart metering system architecture}

"Demand based Smart Metering" is designed to measure the energy consumption during peak and normal hours separately and to send these consumption data periodically to the utility provider through wireless communication. These data are acquired at utility provider server and further used for billing. The smart metering is capable to alert the utility provider if theft is detected and automatically can disconnect the supply to such consumers. Designed system has the feature of remote turn on/off the supply. In India, the time slots from 12:00 AM-06:00 AM, 09:00-06:00 PM and 09:00 PM-12:00 AM can be considered as normal hours and time slots from 06:00 AM-09:00 AM and 06:00-09:00 PM can be considered as peak hours. The time slots can be defined as normal hour I, normal hour II, normal hour III, and peak hour I and peak hour II.

Separate monitoring of energy consumption during these normal and peak hours and applying higher tariff for peak hours would reduce the consumption during peak hours. The system is designed to monitor the energy consumption separately for the normal hours and for two of the peak periods. A limit for the energy consumption during peak hours can be set and load shedding can be imposed for those consumers who cross the limit. This feature force consumers to reduce the energy consumption during peak hours thereby. Figure 6 shows the architecture of SM.

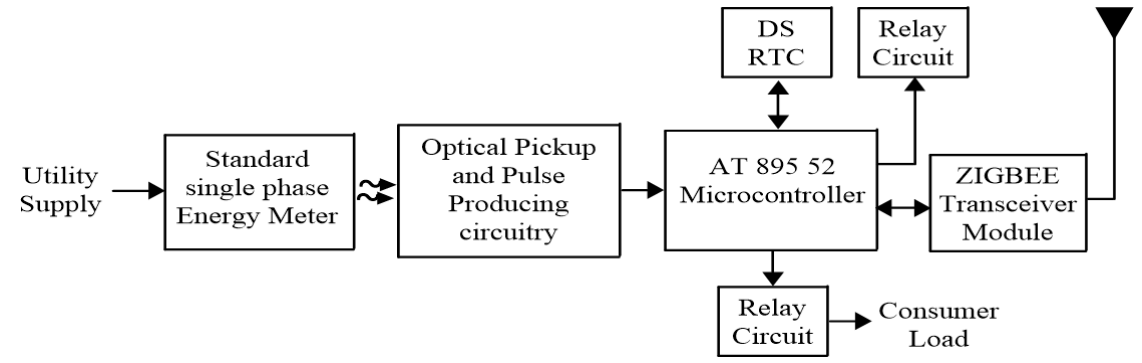

(a)

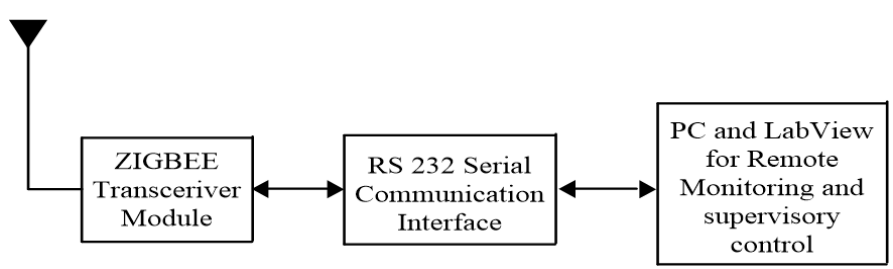

(b)

Figure 6. Architecture of smart meter: (a) Consumer side, (b) Utility provider side

Digital energy meters are installed in such a way that it helps the power company to control the entire customer profile and its power flow. This technique, use GSM network with two-way communication system along with graphical user interface (GUI) communicate with utility and user via SMS. Every SM installed at the end user end has a unique meter ID. In India, developing a low cost basic Smart Meters by upgrading the existing one is more acceptable. That is the system has to be cost-effective such that reduced implementation cost, maintenance free while providing robust and reliable performance. In the proposed design of smart meter, a properly designed optical pick-up circuit is used to generate pulses in accordance with the LED blink/dark marking of the rotating disk of the existing energy meter. AT89S52 microcontroller is used to count the pulses. DS1307

Real time clock (RTC) is used along with the microcontroller to count the pulses separately for the peak and normal hour slots. A single pole double through relay is used to supply end user. Relay provide the feature to cut the supply of power stealers and those whose peak energy consumption limit is also meet. A server computer with GUI or front end, designed using LabVIEW, receives this data and store in a database according to the meter ID. At the end of every month, electricity bill is generated automatically and maintained in the secondary memory of the server. Display of amount of the last bill, bill due dates, alert for theft detect, push switches for remote turn ON/OFF are available at the GUI feature.

\subsection{Smart meter technology evaluation}

Utilities use Smart Meters to smooth running of electric system; various electronic devices in meters provide the two-way communications technology for bidirectional feature $b / w$ consumer and utilities for 
billing and information to communicate or many other features like AMI, AMR. Earlier we used to use one way communication technology, which had many shortcomings. These deficiencies have been overcome by the two-way communications technology. Smart energy meter is the only energy meter with this we can control every type of power tempering attempt and there is no risk of erasing any type of data or evidences in it. Smart energy meter is a group of advanced fast electronic devices. It continuously records the power consumption of the end user with respect to time. Smart meters maintain power consumption records and simultaneously operate monitoring and billing systems. Smart Meter records the typically power use of a consumer per minute of every hour and transfers it through the two-way communication between the smart meter user and utility. Information that is transferred is wireless and along with fast data transfer rate with low power consumption. Smart meter in smart grid Framework: A review paper states that SG is not possible without a smart meter [14], [15].

There is a need of adding some features in our smart grid environment to make the system more energy efficient, to increase the efficiency of the system, to reduce the wastage, to remove the losses. It is possible only when some of the new advanced features like GIS, OMS, EAI, AMI, AMR, MDMS will be in smart grid, these features are not possible without a smart meter [16]. Smart meter provides long term benefits to utility and customers. Data storage, awareness, processing, analysis, tampering attempt, Energy theft detection, power quality monitoring, energy efficiency calculations all this is done within seconds of the help of smart meters [17]. Thorough smart intelligent monitoring system and smart infrastructure communication system, we can reduce our power demand and get very cost benefit analysis. [18]-[20]. Wireless sensor network technology for monitoring system lifts up inside the smart grid [21]. Figure 7 shows the various component of smart energy meter.

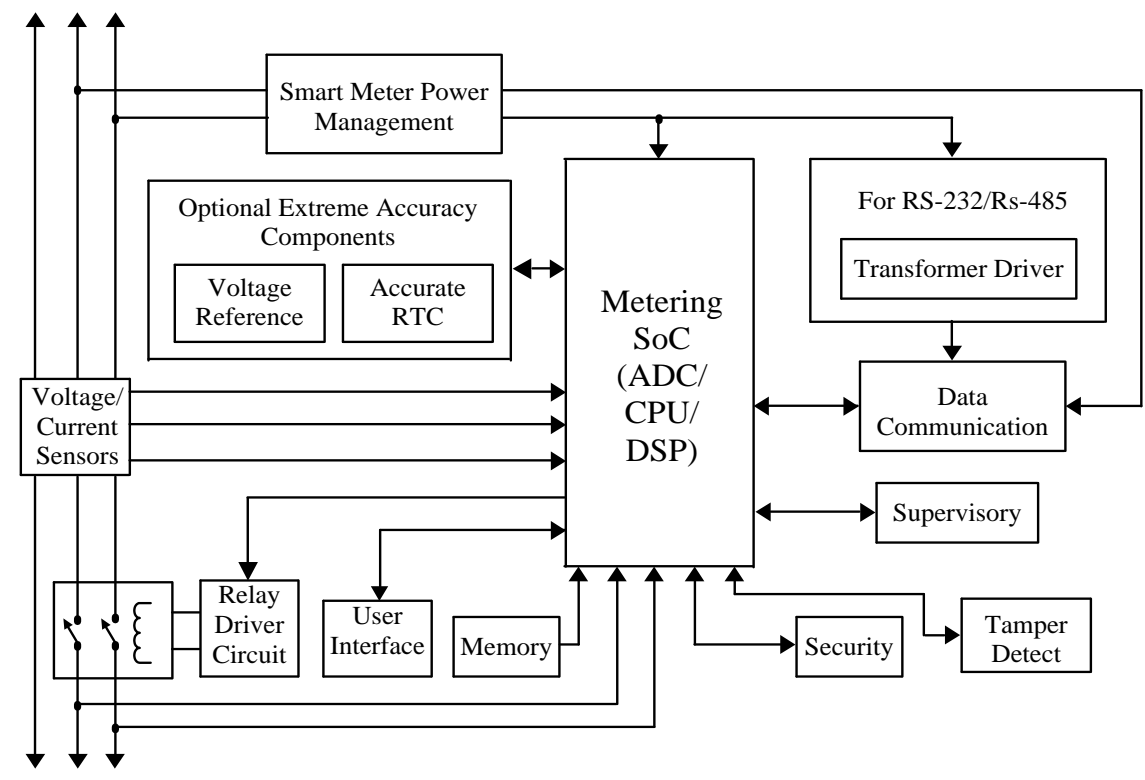

Figure 7. Block diagram of smart energy meter

The smart energy meter implementation increases the reliability of power system by reducing the gap between electricity demand and supply. It provides best possible solution to currently faced challenges like optimization use of energy sources, uninterrupted power supply, losses reduction, theft reduction, data handling [22].

Figure 8 shows various sub system of mater data management system (MDMS). With the help of MDMS, we can identify behavior of our users. We can find out easily which users are involved in theft activity. System also helps us in collecting evidence of the theft performed by the defaulter. After this, there is no need of a physically proofs. It it-self is an evidence of tampering [23]. Entire world's utility suffering from huge amount of revenue loss due to power theft, non-payment of bills, distorted power quality and unnecessary use of electricity. Smart Energy Meter for home Appliances is described in this paper [24]. Not only this, but today's smart meters also include a lot of tempering indication. Indications significantly reduce the tempering impact and power theft activity, chances of theft are equal to zero, and they are considered very strong weapons against power theft. In this way the reliability of the power system will be increased. 


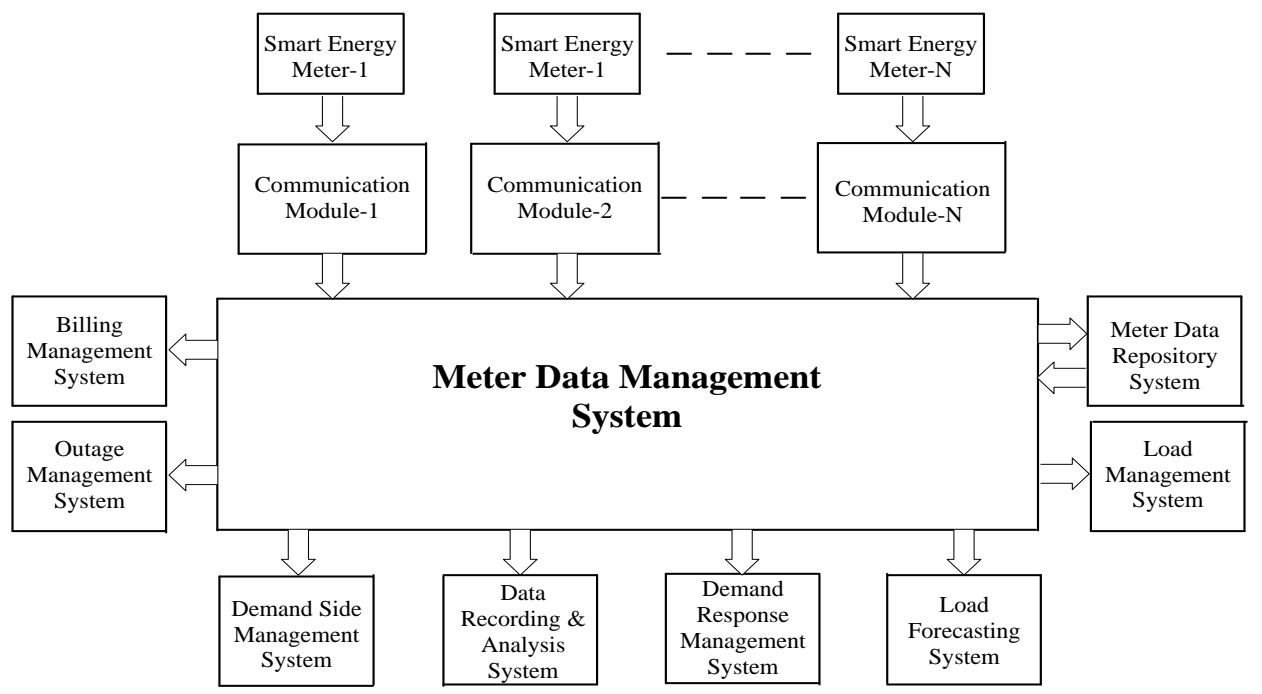

Figure 8. Meter data management system

\section{CONCLUSION}

A comprehensive study is done on energy meters based on their types, principles and power tampering attempts. It also highlighted the problems faced by the utility from billing collection to tracing energy meters and to prevent power theft. In addition, the smart energy meter concept is also discussed. The smart energy meter has the features of maintaining the record of real time-based energy metering and capturing the energy theft. Evidence of power tampering attempts easily captured with the help of data analysis feature of smart energy meter, utility know the information of defaulters as quickly as possible, in this way consumers' theft attempts fail and the utility company's income increases. In addition, smart energy meter supports the requirement of smart grid like DSM, EMS, and load forecasting.

\section{REFERENCES}

[1] R. S. Kumar, T. Raghunatha and R. A. Deshpande, "Segregation of technical and commercial losses in an $11 \mathrm{kV}$ feeder," 2013 7th IEEE GCC Conference and Exhibition (GCC), 2013, pp. 76-79, doi: 10.1109/IEEEGCC.2013.6705752.

[2] R. S. Kumar and M. M. B. Narayanan, "Estimation of AT\&C losses for typical losses for a typical town in Kerala," $22^{\text {nd }}$ National Converntion of Electrical Engineers, Kochi, 2006.

[3] F. D. Garcia, F. P. Marafão, W. A. de Souza and L. C. Pereira da Silva, "Power metering: history and future trends," 2017 Ninth Annual IEEE Green Technologies Conference (GreenTech), 2017, pp. 26-33, doi: 10.1109/GreenTech.2017.10.

[4] G. Platt, S. West and T. Moore, "The real-world challenges and opportunities of distributed generation," 2015 IEEE Energy Conversion Congress and Exposition (ECCE), 2015, pp. 1112-1116, doi: 10.1109/ECCE.2015.7309814.

[5] D. B. P. Quintanilha et al., "Automatic consumption reading on electromechanical meters using HoG and SVM," 7th Latin American Conference on Networked and Electronic Media (LACNEM 2017), 2017, pp. 57-61, doi: 10.1049/ic.2017.0036.

[6] Y. Tang, C. -W. Ten, C. Wang and G. Parker, "Extraction of energy information from analog meters using image processing," in IEEE Transactions on Smart Grid, vol. 6, no. 4, pp. 2032-2040, Jul. 2015, doi: 10.1109/TSG.2015.2388586.

[7] R. Mohassel, A. Fung, F. Mohammadi and K. Raahemifar, "A survey on advanced metering infrastructure," International Journal of Electrical Power and Energy Systems, vol. 63, pp.473-484, 2014, doi: 10.1016/j.ijepes.2014.06.025.

[8] F. R. Clenitiaa, E. Ilakya, G. S. Preetha and B. Meenakshi, "Enhanced digital energy meter," 2017 International Conference on Computation of Power, Energy Information and Commuincation (ICCPEIC), 2017, pp. 588-591, doi: 10.1109/ICCPEIC.2017.8290432.

[9] A. Jain and M. Bagree, "A prepaid meter using mobile communcation," International Jouranl of Engineering, Science anf Technology, vol. 3, no. 3, pp. 160-166, 2011, doi: 10.4314/ijest.v3i3.68432.

[10] Y. Kabalci, "A survey on smart metering and smart grid communication," Renewable and Sustainable Energy Reviews, vol. 57, pp. 302-318, 2016, doi: 10.1016/j.rser.2015.12.114.

[11] T. Akand, Z. Haq and A. A. Mejbah, "Analytical study of impact of prepaid metering system in power distribution sector in Bangladesh," 2019 International Conference on Energy and Power Engineering (ICEPE), 2019, pp. 1-6, doi: 10.1109/CEPE.2019.8726848. 
[12] M. Gupta, S. Gupta and T. Thakur, "A strategic perspective of development of advanced metering infrastructure based Demand Side Management (DSM) model for residential end user," 2014 IEEE International Conference on Power Electronics, Drives and Energy Systems (PEDES), 2014, pp. 1-6, doi: 10.1109/PEDES.2014.7042072.

[13] N. Khan, Y. Naseer, I. Alam, T. Abbas and Y. Iqbal, "Wireless controlled smart digital energy meter and theft control using GSM with GUI," 2018 International Conference on Computing, Mathematics and Engineering Technologies (iCoMET), 2018, pp. 1-6, doi: 10.1109/ICOMET.2018.8346430.

[14] G. R. Barai, S. Krishnan and B. Venkatesh, "Smart metering and functionalities of smart meters in smart grid-a review," 2015 IEEE Electrical Power and Energy Conference (EPEC), 2015, pp. 138-145, doi: 10.1109/EPEC.2015.7379940.

[15] P. Bansal and A. Singh, "Smart metering in smart grid framework: A review," 2016 Fourth International Conference on Parallel, Distributed and Grid Computing (PDGC), 2016, pp. 174-176, doi: 10.1109/PDGC.2016.7913139.

[16] S. Jain, V. Kumar N., A. Paventhan, V. K. Chinnaiyan, V. Arnachalam and Pradish M., "Survey on smart grid technologies- smart metering, IoT and EMS," 2014 IEEE Students' Conference on Electrical, Electronics and Computer Science, 2014, pp. 1-6, doi: 10.1109/SCEECS.2014.6804465.

[17] N. L. Andrei, V. Tanasiev, M. Sanduleac and A. Badea, "Smart metering platform as a solution for data analysis," 2017 International Conference on ENERGY and ENVIRONMENT (CIEM), 2017, pp. 495-499, doi: 10.1109/CIEM.2017.8120798.

[18] Y. Yan, Y. Qian, H. Sharif and D. Tipper, "A survey on smart grid communication infrastructures: Motivations, requirements and challenges," in IEEE Communications Surveys and Tutorials, vol. 15, no. 1, pp. 5-20, First Quarter 2013, doi: 10.1109/SURV.2012.021312.00034.

[19] J. Genet and C. Schubert, "Designing a metering system for small and medium-sized buildings," Technical Report SEMED310007EN, SE, 2011.

[20] S. S. S. R. Depuru, L. Wang and V. Devabhaktuni, " Smart meters for power grid: Challenges, issues, advantages and status," Renewable and Sustainable Energy Reviews, vol. 15, no. 6, pp. 2736-2742, 2011, doi: 10.1016/j.rser.2011.02.039.

[21] M. F. Othmana and K. Shazalib, "Wireless sensor network applications: a study in environment monitoring system," Procedia Engineering, vol. 41, pp. 1204-1210, 2012, doi: 10.1016/j.proeng.2012.07.302.

[22] S. Fuada, "Proposed an intelligent system for electricity theft detector at smart city scenarios," International Journal of Applied Power Engineering (IJAPE), vol. 5, no. 1, pp. 51-58, Apr. 2016, doi: 10.11591/ijape.v5.i1.pp5158.

[23] J. Zheng, D. W. Gao and L. Lin, "Smart meters in smart grid: An overview," 2013 IEEE Green Technologies Conference (GreenTech), 2013, pp. 57-64, doi: 10.1109/GreenTech.2013.17.

[24] H. Das and L. C. Saikia, "GSM enabled smart energy meter and automation of home appliances," 2015 International Conference on Energy, Power and Environment: Towards Sustainable Growth (ICEPE), 2015, pp. 15, doi: 10.1109/EPETSG.2015.7510071.

\section{BIOGRAPHIES OF AUTHORS}

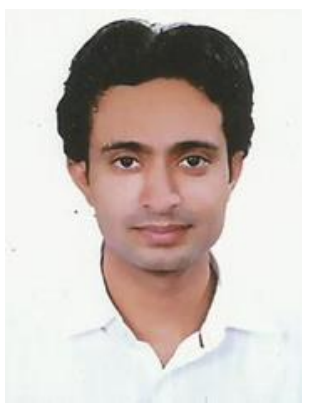

Manoj Saini, Research Scholar, School of Electrical, Electronics and Communication Engineering, Galgotias University, Gr. Noida. Uttar Pradesh, India, M-Tech: Electrical Engineering (Power System), D.C.R.U.S.T, Murthal, Sonipat, in 2011, B.E.: Electrical Engineering, C.R.S.C.E, Murthal, Sonipat, Haryana, in 2009. Currently working as Assistant Professor in Electrical Engineering Department, Galgotias College of Engineering and Technology, 1, Knowledge Park, Phase II, Greater Noida, Uttar Pradesh 201306, Since 01 Dec 2014 to till date. Research Area: Renewable Energy Generation, Power system and Energy Auditing, Teaching Experience: 7 years.

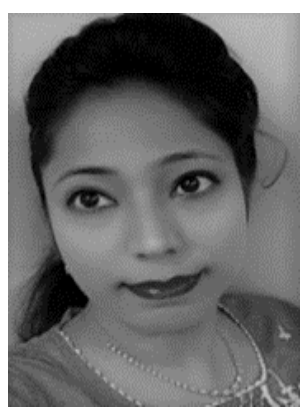

Shagufta Khan, Assistant Professor, School of Electrical, Electronics and Communication Engineering, Galgotias University, Gr. Noida. She received the Ph.D. degree in electrical engineering from Delhi Technological University, Delhi, India. She is currently an Assistant Professor with the School of Electrical, Electronics and Communication Engineering, Galgotias University, Greater Noida, India. Her research interests include power systems and renewable energy. 